\title{
Effect of high pressure soaking on water absorption, gelatinization, and biochemical properties of germinated and non- germinated Foxtail millet grains
}

Article

Accepted Version

Sharma, N., Goyal, S. K., Alam, T., Fatma, S., Chaoruangrit, A. and Niranjan, K. (2018) Effect of high pressure soaking on water absorption, gelatinization, and biochemical properties of germinated and non-germinated Foxtail millet grains. Journal of Cereal Science, 83. pp. 162-170. ISSN 0733-5210 doi: https://doi.org/10.1016/j.jcs.2018.08.013 Available at https://centaur.reading.ac.uk/79842/

It is advisable to refer to the publisher's version if you intend to cite from the work. See Guidance on citing.

To link to this article DOI: http://dx.doi.org/10.1016/j.jcs.2018.08.013

Publisher: Elsevier

All outputs in CentAUR are protected by Intellectual Property Rights law, including copyright law. Copyright and IPR is retained by the creators or other copyright holders. Terms and conditions for use of this material are defined in the End User Agreement. 


\section{www.reading.ac.uk/centaur}

\section{CentAUR}

Central Archive at the University of Reading

Reading's research outputs online 


\title{
Effect of high pressure soaking on water absorption, gelatinization, and biochemical properties of germinated and non-germinated Foxtail millet grains
}

\author{
Nitya Sharma ${ }^{\mathrm{a}}$, S. K. Goyal ${ }^{\mathrm{a}}$, Tanweer Alam ${ }^{\mathrm{b}}$, Sana Fatma ${ }^{\mathrm{c}}$, Araya Chaoruangrit ${ }^{\mathrm{d}}$, \\ Keshavan Niranjan ${ }^{\mathrm{e}}$
}

aDepartment of Farm Engineering, Institute of Agricultural Sciences, Banaras Hindu University, Varanasi (India)

${ }^{\mathrm{b}}$ Indian Institute of Packaging, New Delhi (India)

${ }^{c}$ Centre of Food Science and Technology, Banaras Hindu University, Varanasi (India)

${ }^{\mathrm{d}}$ Faculty of Food Technology, Khon Kaen University, Khon Kaen (Thailand)

${ }^{\mathrm{e}}$ Department of Food and Nutritional Sciences, University of Reading, Reading (UK)

\begin{abstract}
Foxtail millet, extensively grown in Asia, Africa and China, is one of the few crops that can thrive under relatively few agricultural inputs and have valuable amount of nutritional components. Therefore, processing of foxtail millet for value addition to various food products can significantly help in economic development as well as enhancing food and nutritional security. This study deals with the effect of high pressure soaking on water uptake, gelatinization characteristics, and nutritional and anti-nutritional properties of foxtail millet grains and its flour. The results demonstrated that high pressure soaking of germinated foxtail millet grains significantly increased the water uptake, thereby increasing the degree of starch gelatinization of the flour to attain a maximum value of $64.93 \%$. The effective diffusion coefficient of water was found to increase with increasing pressures and temperatures, reaching maximum value of $6.77 \times 10^{-9} \mathrm{~m}^{2} \mathrm{~s}^{-1}$ for germinated foxtail millet grains treated at $200 \mathrm{MPa}$ and $60{ }^{\circ} \mathrm{C}$. In terms of nutrient content of germinated foxtail millet grain flour, the total phenolic content and antioxidant activity (FRAP assay) improved significantly, although
\end{abstract}


the protein content did not vary significantly. Further, the levels of anti-nutrients (phytic acid and tannin) decreased with high pressure soaking, which conclusively establishes that the quality of foxtail millet grains and its flour can be improved by using high pressure soaking.

\section{Introduction}

Foxtail millet (Setaria italica (L.) P. Beauv.) is one of the oldest cultivated crops, identified as a major millet in terms of worldwide production. It belongs to the Setaria genus, of Poaceae family and subfamily Panicoideae. Foxtail millet is known to contain a useful amount of nutritional components along with some anti-nutritional components (Sharma \& Niranjan, 2017). In addition, this millet has also shown to possess several health benefits like cancer prevention, hypoglycemic and hypolipidemic effects (Zhang et al., 2015). A detailed review on foxtail millet properties, processing and applications has recently been published (Sharma \& Niranjan, 2017).

Germination generally enhances the health functional properties of the seeds. There is growing interest in the process of germination because it yields what is perceived to be natural, minimally processed and highly nutritious products. In the case of millets, germination is known to increase the yield of hydroxyl radical-inhibiting water-soluble protein (Bai et al., 2009). This is also true of foxtail millets, whose germination has been reported to enhance levels of total phenolics, antioxidants, total flavonoids, dietary fibre, proteins and minerals, whilst lowering the antinutritional factors (Sharma et al., 2015; Nazni \& Shobana, 2016). These earlier studies have also reported that the functional properties of germinated foxtail millet are influenced by the pre-germination water soaking conditions as well as the germination conditions which can potentially be optimised to yield the right levels of phytochemicals. 
A novel method to improve the kinetics and quantities of water absorbed during soaking, and therefore positively transform the germinated product, is the use of highpressures during soaking. This technique has been successfully used to improve the quality of wheat and rice brans (Özkaya et al., 2016), brown rice (Xia et al., 2016), and rough rice (Kim et al., 2017). The application of high hydrostatic pressure during soaking has been reported to enhance nutrition, and lower anti-nutritional factors including the formation of allergens and other contaminants (Barba et al., 2015). But there are also reports to the contrary which state that the effects of high pressure application vary with the structure and composition of food as well as other dynamic parameters of the processing technique, and there is no conclusive correlation between the application of high pressure and the formation of nutrients/antinutrients (Xia et al., 2016). Given the conflicting reports on the effects of high pressure soaking prior to seed germination, this paper first investigates the effect of germination on the properties of foxtail millet grains, and then evaluates the combined effect of pressures, temperatures and soaking times on the properties of non-germinated and germinated foxtail millet grains and its flour.

\section{Materials and methods}

\subsection{Sample preparation}

The samples were prepared by subjecting viable foxtail millet grains to germination and high pressure soaking as described by Sharma et al. (2018). Both germinated and nongerminated foxtail millet grains $(25 \mathrm{~g}$ each) were subjected to high hydrostatic pressures in a temperature-controlled pressure vessel system (vessel dimensions: $37 \mathrm{~mm}$ diameter and 246mm length, Food LAB 900, Stansted Fluid Power Ltd., Stansted, UK). Following an earlier study conducted on Thai glutinous rice by Ahromrit et al. (2006), the high-pressure processing experimental design for foxtail millet grains consisted of three levels of pressure 
$(200,400$ and $600 \mathrm{MPa})$, four levels of temperature $\left(20,40,60\right.$ and $\left.80{ }^{\circ} \mathrm{C}\right)$ and four levels of time $(30,60,90$ and $120 \mathrm{~min})$. The $25 \mathrm{~g}$ foxtail millet grain samples were suspended in $150 \mathrm{ml}$ of deionised water and sealed in polyethylene pouches of dimensions $3 \mathrm{~cm} \times 20 \mathrm{~cm}$ by employing Cryovac ${ }^{\mathrm{TM}}$. Following high-pressure processing of the grains, the water was completely drained from the pouches and the water occluding to the grains separated, was then blotted using a tissue paper. The water uptake in both germinated and non-germinated foxtail millet grains was analysed soon after high pressure soaking. The remaining germinated and non-germinated foxtail millet grain samples were then dried to a final moisture content of $10 \pm 2 \%$ and finely grinded in a laboratory miller. The finely ground flour was then passed through a 100 -mesh sieve $(150 \mu)$, to ensure the removal of non-edible husk portion of foxtail millet grains.

\subsection{Determination of moisture content}

The moisture content (wet weight basis) was determined using a Sartorious MA 40 moisture analyser (Sartorious, Goettingen, Germany). Approximately 5-7g of the soaked grains were placed in the moisture analyser at $105^{\circ} \mathrm{C}$ and dried to a constant weight.

\subsection{Determination of effective diffusion coefficient of water}

Karizaki et al. (2016) proposed a method to determine the effective diffusion coefficient of water for rice cooking. A similar approach, with some modifications, was used to characterise water absorption into foxtail millet grains: (i) the grains were considered to be a small homogenous sphere, whose dimensions did not vary during processing; (ii) the moisture was distributed uniformly in the grain; (iii) the concentration gradient was considered to operate radially; (iv) the convective mass transfer coefficients and effective moisture diffusivity were considered to be independent of moisture contents; (v) the system velocities and water production/consumption by chemical reactions were considered to be 
negligible during the process; and finally, (v) the high pressure treatment of foxtail millet grains was considered to be isothermal under all pressure conditions as the adiabatic temperature rise was momentary due to longer periods of pressure application.

The simplified continuity equation employed was as follows (Karizaki et al., 2016):

$\frac{\partial C_{w}}{\partial t}=D_{e f f}\left[\frac{1}{r^{2}} \frac{\partial}{\partial r}\left(r^{2} \frac{\partial C_{w}}{\partial r}\right)\right]$

where $C_{w}(r, t)$ is the moisture content at any point $(r)$ and any time $(t)$, and $D_{\text {eff }}\left(\mathrm{m}^{2} / \mathrm{s}\right)$ is the effective moisture diffusivity. The initial and boundary conditions employed were:

I. $C \rightarrow C_{w}(r, 0)=C_{i}$

B.C $(1) \rightarrow C_{w}(0, t)=$ finite

B.C (2) $\rightarrow-D_{\text {eff }} \frac{\partial C_{w}\left(r_{0}, t\right)}{\partial r}=K_{c}\left(C_{\infty}-C_{w}\left(r_{0}, t\right)\right)$

where $C_{i}$ and $C_{\infty}$ are the initial moisture content of foxtail millet grains and moisture content of the medium in which the grains are treated (in percent dry basis), respectively; and $K_{c}$ $(\mathrm{m} / \mathrm{s})$ and $r_{0}(\mathrm{~m})$ are the convective mass transfer coefficient and the radius of the spherical grain, respectively. The solution of Eq. (1) as reported by Mosavian \& Karizaki (2012) is:

$\frac{C_{w}(r, t)-C_{\infty}}{C_{i}-C_{\infty}}=\frac{\frac{\sin \left(r_{0} \lambda_{1}\right)}{\lambda_{1}^{2}}-\frac{r_{0} \cos \left(r_{0} \lambda_{1}\right)}{\lambda_{1}}}{\frac{r_{0}}{2}-\frac{\sin \left(2 r_{0} \lambda_{1}\right)}{4 \lambda_{1}}} \times \frac{\sin \left(r \lambda_{1}\right)}{r} e^{-D_{e f f} \lambda_{1}^{2} t}$

where, $\lambda_{1}$ is the root of the characteristic equation for a spherical solid. The average grain moisture content at time $t$ has also been reported by Mosavian \& Karizaki (2012) to be:

$\ln \left(\frac{\bar{C}(t)-C_{\infty}}{C_{i}-C_{\infty}}\right)=\ln (\psi)-D_{e f f} \lambda_{1}^{2} t$

where:

$\psi=\frac{6\left(\sin \left(r_{0} \lambda_{1}\right)-r_{0} \lambda_{1} \cos \left(r_{0} \lambda_{1}\right)\right)^{2}}{\left(r_{0} \lambda_{1}\right)^{3}\left(r_{0} \lambda_{1}-\sin \left(r_{0} \lambda_{1}\right) \cos \left(r_{0} \lambda_{1}\right)\right)}$ 
Finally, $D_{\text {eff }}$ and $\Psi$ were determined from the plot of $\ln \left(\frac{\bar{C}(t)-C_{\infty}}{C_{i}-C_{\infty}}\right)$ against time, using the values of $\lambda_{1}$ - the root of characteristic equation for a spherical solid - reported by Mosavian \& Karizaki (2012).

\subsection{Differential scanning calorimetry (DSC)}

A suspension of high pressure soaked germinated and non-germinated foxtail millet flour was prepared in deionised water at a ratio of 1:3; equilibrated for 15-18 $\mathrm{h}$ at ambient temperature; and analysed using a differential scanning calorimeter, equipped with a built-in software (Model Q 2000a TA Instruments, New Castle, U.S.A.). A 10-12 mg suspension sample was weighed precisely in an aluminium sample pan and hermetically sealed. A similar empty pan was used as a reference for the analysis. A temperature range of 10 to 140 ${ }^{\circ} \mathrm{C}$ was used for scanning the sample in the pan at a heating rate of $10{ }^{\circ} \mathrm{C} \mathrm{min}{ }^{-1}$. The resulting thermogram gave the values of onset $\left(\mathrm{T}_{\mathrm{o}}\right)$, peak $\left(\mathrm{T}_{\mathrm{p}}\right)$ and conclusion temperatures $\left(\mathrm{T}_{\mathrm{c}}\right)$ in ${ }^{\circ} \mathrm{C}$ and gelatinisation enthalpies $(\Delta \mathrm{H})$ in $\mathrm{kJ} \mathrm{kg}^{-1}$. The final values obtained were an average of three replicates for each sample, with a maximum deviation of less than $1.5 \%$. The gelatinisation enthalpies of high pressure treated foxtail millet grain samples $\left(\Delta \mathrm{H}_{\mathrm{HP}}\right)$ were compared with the enthalpy of raw foxtail millet grain sample $\left(\Delta \mathrm{H}_{\mathrm{R}}\right)$, thus, giving the degree of starch gelatinization (DSG) (Zhu et al., 2016):

$\operatorname{DSG}(\%)=1-\frac{\Delta H_{H P}}{\Delta H_{R}} \times 100$

2.5. Determination of the effect of germination and HPP on nutritional and antinutritional properties

\subsubsection{Chemical composition}


The crude protein content was determined using Kjeldahl method with an analyser unit (AOAC, 1995). A conversion factor of 6.25 was used to quantify the crude protein content. Fat and total dietary fibre content was determined by the method of AOAC (1995).

\subsubsection{Total phenolic content}

The free phenolics of foxtail millet grain samples were extracted using $80 \%$ acetone, and the total phenolic content of the extracts was determined using the method described by Zhang \& Liu (2015). In this method, diluted extracts were reacted with Folin-Ciocalteu reagent, followed by neutralization of this reaction using sodium carbonate. This resulted in the formation of a blue colour with time that indicated the presence of phenolics in the samples. The absorbance of this blue colour was then measured at $760 \mathrm{~nm}$ at room temperatures. The total phenolic content was expressed as $\mathrm{mg}$ of gallic acid equivalent per100g of sample. The values obtained were an average of three replicates.

\subsubsection{Antioxidant activity}

The antioxidant activity was determined by measuring the ferric reducing antioxidant power (FRAP) of the foxtail millet grain samples, as per the method described by Shejawale et al. (2016). For the estimation, a FRAP reagent containing acetate buffer, 2,4,6-tripyridyl-Striaizine (TPTZ) and ferric chloride was prepared in the ratio of 10:1:1, and added to the diluted extract. The absorbance of the resulting solution was measured at $593 \mathrm{~nm}$ and the mean value of three replicates was expressed as $\mu \mathrm{mol} / \mathrm{g}$.

\subsubsection{Antinutritional factors}

The phytic acid content of foxtail millet grain samples were determined using a phytic acid assay kit (Megazyme International Ireland, Bray, Ireland). The results were the mean of three replicates, expressed in $\mathrm{g} / 100 \mathrm{~g}$. The tannin content was analysed using the Vanillin-HCl 
method given by Price \& Butler (1987), with some modifications. The tannin concentration corresponding to the measured optical density was expressed in $\mathrm{mg} / 100 \mathrm{~g}$ on dry weight basis.

\subsection{Experimental design and statistical analyses}

In this study, a three-factor general factorial design was obtained using Minitab 17 software for Microsoft windows. This design was used to investigate the effect of interaction between the process variables on the response variables and optimize the nutritional and antinutritional properties for germinated foxtail millet grains. The results obtained from each set of experiments were analysed statistically using one-way analysis of variance (ANOVA) and the mean of triplicate experimental values along with their standard deviations were reported. The difference among the experimental treatments was determined using least significant difference (LSD). Statistical significance was set at $\mathrm{p}<0.05$.

\section{Results and discussion}

\subsection{Water uptake}

The water uptake by the foxtail millet grains increased with soaking pressures and temperatures for both germinated and non-germinated samples. Germination increased the water uptake of the grains by $3.13 \%$ due to rupture of outer walls of the grain. A difference test was performed on the moisture content values obtained for germinated and nongerminated grains at a given pressure, temperature and time, which revealed that the rate of increase in moisture content of germinated grains was higher compared to the nongerminated samples. Fig. $1(\mathrm{a}, \mathrm{b})$ shows the interaction plot for water uptake of germinated and non-germinated foxtail millet grains with soaking time at different pressures and temperatures. It is evident from the figures that the moisture content of grains increases with time, which then levels off eventually in case of germinated grains. Although, there is no significant change in the water uptake values of germinated grains with time and at pressures 
above $400 \mathrm{MPa}$, but a sharp rise in the moisture was observed at temperatures above $40{ }^{\circ} \mathrm{C}$. These results were in agreement with a study done by $\mathrm{Yu}$ et al. (2016) who reported that soaking brown rice at higher pressures and temperatures yield higher values of final moisture content values which seem independent of time. Yu et al (2016) has referred to this value as equilibrium moisture content (EMC) for brown rice, while in case of foxtail millet it is unclear whether water absorption is thermodynamically an equilibrium process. Therefore, this value can be considered as the maximum value of moisture content achievable whilst high pressure soaking at a given temperature for a specific period. The reason for higher values of final moisture content resulting at higher soaking temperature and pressures appears to be due to the formation of more cracks on the surface of the grains which seem to allow more water to penetrate. Zhu et al. (2016) have stated that processing of grains causes removal or destruction of protective outer bran layers, especially the hydrophobic lipid layer, thereby increasing water diffusion during high pressure soaking. Similar results were reported stating that high pressure soaking increased the moisture content of Jasmine rice (BoludaAguilar et al., 2013) as well as Thai glutinous rice (Ahromrit et al., 2006).

It can be concluded from the plots shown in fig. $1(\mathrm{a}, \mathrm{b})$ that the rate of attaining maximum moisture content under high pressure soaking was greater in the case of germinated foxtail millet grains as compared to the non-germinated grains.

\subsection{Values of $D_{\text {eff }}$}

The values of $D_{\text {eff }}$ for different combinations of pressures and temperatures are shown in fig. 2 (a) for germinated grains and in fig. 2 (b) for non-germinated grains. The values obtained of $D_{\text {eff }}$ varied from $2.22 \times 10^{-9}$ to $6.77 \times 10^{-9} \mathrm{~m}^{2} \mathrm{~s}^{-1}$ for germinated foxtail millet grains, the highest value being for grains treated at $200 \mathrm{MPa}$ and $60{ }^{\circ} \mathrm{C}$ and lowest being for grains treated at $0.1 \mathrm{MPa}$ and $20{ }^{\circ} \mathrm{C}$. The $D_{\text {eff }}$ values for non-germinated grains ranged between 
$1.58 \times 10^{-9}\left(0.1 \mathrm{MPa}\right.$ and $\left.20{ }^{\circ} \mathrm{C}\right)$ to $5.65 \times 10^{-9} \mathrm{~m}^{2} \mathrm{~s}^{-1}\left(400 \mathrm{MPa}\right.$ and $\left.80{ }^{\circ} \mathrm{C}\right)$. The $D_{\text {eff }}$ values for germinated grains increased with temperature until $60{ }^{\circ} \mathrm{C}$ and then dropped significantly at 80 ${ }^{\circ} \mathrm{C}$. Also, the $D_{\text {eff }}$ values for germinated grains increased till soaking pressures of $200 \mathrm{MPa}$, subsequently decreasing at higher pressures (Fig. 2-a). On the other hand, the plot for nongerminated foxtail millet grains (Fig. 2-b) depicted an increase in $D_{\text {eff }}$ values with increasing temperatures $\left(20\right.$ to $80{ }^{\circ} \mathrm{C}$ ) and increasing pressures till $400 \mathrm{MPa}$, with a significant drop at $600 \mathrm{MPa}$. The reason behind this unique pattern in the effective diffusion coefficient values of foxtail millet grains could be gelatinization of starch, which makes it very similar in terms of effective diffusion to other starch-rich grains like rice, wheat, maize, etc. (Kashaninejad et al., 2007). Since germination of foxtail millet grains also contributed to its permeability by opening up the grain surface due to fresh cracks, therefore the maximum value of $D_{\text {eff }}$ $\left(6.77 \times 10^{-9} \mathrm{~m}^{2} \mathrm{~s}^{-1}\right)$ was obtained for germinated grains at $200 \mathrm{MPa}$ and $60{ }^{\circ} \mathrm{C}$ and the minimum $\left(1.58 \times 10^{-9} \mathrm{~m}^{2} \mathrm{~s}^{-1}\right)$ for non-germinated grains at $0.1 \mathrm{MPa}$ and $20{ }^{\circ} \mathrm{C}$.

It can therefore be concluded that high pressures and high temperatures effectively enhance water diffusion in germinated foxtail millet grains as compared to non-germinated foxtail millet grains, but only up to a point where starch is not significantly gelatinised. Therefore, the differential behaviour in the degree of gelatinization has also been studied for both germinated and non-germinated samples.

\subsection{Gelatinisation of starch}

Different degrees of starch gelatinization were observed following soaking of germinated and non-germinated foxtail millet grains at high pressures and temperatures. The gelatinization temperatures represent the structural stability of starch molecules, while the gelatinization enthalpy indicates the loss of molecular order of starch granules due to breaking of hydrogen bonds. The values of onset $\left(\mathrm{T}_{\mathrm{o}}\right)$, maximum $\left(\mathrm{T}_{\mathrm{m}}\right)$ and conclusion $\left(\mathrm{T}_{\mathrm{c}}\right)$ 
gelatinization temperatures and gelatinization enthalpy $(\Delta \mathrm{H})$ of control and high pressure soaked foxtail millet samples showed that the native starch exhibited higher gelatinization temperatures and enthalpies compared to all the high pressure treated samples. Li et al. (2004) has explained this difference in the values of gelatinization properties in terms of type and concentration of starch, amylose-amylopectin ratio and nutritional composition of grain samples. Similar results concluding decreases in the gelatinization temperatures and enthalpies with increasing pressures and temperatures have also been reported for brown rice (Zhu et al., 2016) and rice flour (Li et al., 2012).

Higher gelatinization temperatures and enthalpies for non-germinated samples as compared to the germinated samples, indicating that the process of germination reduces the resistance to high pressure induced gelatinization of foxtail millet grains, that could be due to distortion of starch granular structure that took place during high pressure treatment (Liu et al., 2009).

The degree of starch gelatinisation for both non-germinated and germinated foxtail millet grains soaked under various combinations of pressures, temperatures and times are shown in fig. $3(a, b)$, which also shows the effect of interaction between the factors. The results stated that longer the period of high pressure soaking and higher the temperatures, higher the degree of starch gelatinisation for both germinated and non-germinated grains. The starch gelatinization from $0.51 \%$ to $64.93 \%$ for germinated samples and from $0.32 \%$ to $55.21 \%$ from non-germinated samples, thus carrying out only partial gelatinization in both samples. The interaction plot also shows that high pressures had a significant effect on the degree of starch gelatinization of both germinated and non-germinated grains, with a rapid increase in gelatinization till $400 \mathrm{MPa}$ in a temperature range of 20 to $60{ }^{\circ} \mathrm{C}$. The results were in agreement with the findings of Tan et al. (2009), who stated that pressure treatment induces starch gelatinization more gradually than temperature treatment and Zhu et al. 
(2016), who defined high pressure treatment of brown rice at $400 \mathrm{Mpa}$ for $10 \mathrm{~min}$ as threshold values for degree of starch gelatinization. In general, the factors affecting the degree of starch gelatinization are sample characteristics, water absorption capacity and the type of starch. Apart from this, presence of protein has also been found to decrease the percentage of starch gelatinization even at high pressures (Ahmed et al., 2007). Similarly, the effect of high pressure treatment on the starch gelatinization properties has been studied for basmati rice flour slurry (Ahmed et al., 2007); Thai glutinous rice (Ahromrit et al., 2007); japonica rice starch (Tan et al., 2009); rice starch (Li et al., 2012); rice (Boluda-Aguilar et al., 2013); wheat starch (Qiu et al., 2014) and brown rice (Zhu et al., 2016).

Therefore, the study concluded that starch gelatinisation in germinated foxtail millet grains is higher as compared to non-germinated foxtail millet grains. This may be due to higher permeability of grains after germination and high pressure soaking of grains. This implies that high pressure soaking of germinated foxtail millet grains can produce better partially gelatinized/cooked grain or flour, as compared to non-germinated foxtail millet grains.

\subsection{Effect of germination on nutritional and anti-nutritional properties}

Various researchers have studied the effect of germination on the nutritional and antinutritional properties of foxtail millet (Sharma et al., 2015 and Nazni \& Shobana et al., 2016). These studies revealed that the process of germination significantly affected the nutritional properties like protein, fat, total dietary fibre, total phenolic content and antioxidant activity, along with certain anti-nutritional properties like phytic acid and tannin content. Table 1 shows the change in the values of nutritional and anti-nutritional properties before and after germination of foxtail millet grains. The results show that germination of foxtail millet grains increased the protein, total dietary fibre and total phenolic content by $29.72 \%, 58.02 \%$ and 
$77.42 \%$, respectively; ferrous ion reducing antioxidant potential by $109.50 \%$; and reduced the fat content by $27.98 \%$. This could be due to intrinsic biosynthesis of free and soluble forms of nutrients in germinated foxtail millet gain samples through enzymatic reaction during germination process (Xia et al., 2016). Along with this, the anti-nutritional properties like phytic acid and tannin content was decreased by $39.02 \%$ and $45.07 \%$, respectively. Hydrolysis of phytate phosphorus into inositol monophosphate due to phytase activity is responsible for the decrease in phytic acid, while, the decrease in tannin content could be due to the breakdown of tannin compounds in water during soaking and germination (Sharma et al., 2015; Kakati et al., 2010).

Therefore, the results of this study established the fact that germination significantly improved the nutritive value of foxtail millet grains. These germinated grains can then be used for development of some new foods products.

\subsection{Effect of high pressure processing on nutritional and anti-nutritional properties}

Further, with an aim to design a ready-to-cook flour that can used as an ingredient in food products like porridges and other snacks, the effect of high pressure treatment was studied on their nutritional and anti-nutritional properties. Following the positive effects of germination on foxtail millet grains, the combined effect of increasing pressures, temperatures and soaking time was also studied on the nutritional quality of germinated foxtail millet grain flour. Results showed both significant and non-significant change in the nutritional and anti-nutritional properties of germinated foxtail millet grain flour treated at high pressures and different temperatures for various soaking periods.

The protein content of the germinated foxtail millet grain flour did not change significantly with high pressure treatment. The values ranged between $13.65 \%$ (native germinated grains) to $13.11 \%\left(600 \mathrm{MPa}, 60{ }^{\circ} \mathrm{C}\right.$ and $\left.120 \mathrm{~min}\right)$. Table 2 shows the effect of 
process variables (pressures, temperatures and soaking times) and on the protein content of germinated foxtail millet grain flour. This reduction in protein content could be due to the formation of a protein-starch complex or due to hydrogen/covalent/ionic bonding between protein and starch molecules. Kakati et al. (2010) also stated that pressure cooking slightly decreased the protein content as compared to other processing treatments like soaking, and germination.

According to the results (table 2), the total phenolic content was found to increase by $17.09 \%$ with increasing pressures and times on treating the germinated foxtail millet grain flour at $20{ }^{\circ} \mathrm{C}$. These results observed at ambient temperatures complied with a study done by Kim et al. (2017) on the effect of high hydrostatic pressures (100 MPa for $24 \mathrm{~h}$ ) on germinated rough rice. According to them, this enhancement in the total phenolic content was due to increased rate of mass transfer at high pressures that increases the solvent extraction ability of the grains through disruption of cellular walls and hydrophobic bonds. The results of mass transfer studies in this article have shown that soaking of germinated foxtail millet grains at high pressures and temperatures increase the rate of mass transfer, thus justifying the results of studies done by Kim et al. (2017). While, the total phenolic content of the native germinated foxtail millet grain flour was also found to decrease slightly by $20.36 \%$, as compared to the flour from grains treated at $600 \mathrm{MPa}$ and $40{ }^{\circ} \mathrm{C}$ for $120 \mathrm{~min}$ and by $26.55 \%$, as compared to the flour from grains treated at $600 \mathrm{MPa}$ and $60{ }^{\circ} \mathrm{C}$ for $120 \mathrm{~min}$. Since the major part of millet phenolics are found in free form present in the pericarp and aleurone layer of the grain (Dykes \& Rooney et al., 2006), therefore, subjecting these germinated foxtail millet grains to high temperature induces chemical oxidation of free water-soluble polyphenols leached into boiled water (Özkaya et al., 2016).

The antioxidant activity of high pressure soaked germinated foxtail millet grain flour, determined using the FRAP assay, depicted an interesting trend with increasing pressures, 
temperatures and times. Table 2 shows that as the pressure, temperature and soaking time increased, the ferrous reducing potential of the flour also increased. The differential increase in the antioxidant activity of native germinated foxtail millet grain flour and the flour of germinated grains treated at $600 \mathrm{MPa}$ and $60{ }^{\circ} \mathrm{C}$ for 120 mins was calculated to be $105.33 \%$. Xia et al. (2016) stated that the turbulence and shear caused by high pressure treatment of brown rice caused the disruption of cell walls and organelles, thus improving the extraction ability of the antioxidant compounds and releasing them into the extracellular surroundings. While, thermal treatment of wheat and rice bran involving high pressurized steam were also found to increase the antioxidant activity owing to the formation of Millard reaction products having antioxidant properties (Özkaya et al., 2016). Similarly, higher antioxidant potential of the germinated foxtail millet grains was seen at higher pressures and temperatures.

Results in table 2 also illustrates the effect on the anti-nutritional properties due to the interaction between the process variables, i.e. high pressure and temperature treatment for specific time periods. It was clear from the results that both phytic acid and tannin content decreased with the increase in pressures, temperatures and soaking times. The native germinated foxtail millets grain flour possessed $0.5421 \%$ and $0.0016 \%$ of phytic acid and tannin content, respectively. High phytic acid content in the flour might be due to the presence of traces of the finely ground husk/hull portion of foxtail millet grains. Further, the phytic acid and tannin content was reduced to negligible amounts of $0.1870 \%$ and $0.0006 \%$, respectively, after high pressure and temperature treatment at $600 \mathrm{MPa}$ and $60{ }^{\circ} \mathrm{C}$ for 120 mins. The maximum decrease of $67.87 \%$ in phytic acid content was observed till a pressure of $400 \mathrm{MPa}$ and temperature of $40{ }^{\circ} \mathrm{C}$ at all three soaking times. However, increasing the pressures, temperatures and soaking times above this level did not make a significant difference in the phytic acid loss of germinated foxtail millet samples even on increasing the temperatures and times. Also, a minimum reduction in phytic acid content was reported at 
atmospheric pressures, even on increasing the temperatures and soaking times at this pressure (table 2). Degradation of phytic acid on treating the germinated foxtail millet grains at high pressures, temperatures and times, is possibly due to increased solubility of phytic acid-cation complexes, as is for rice and wheat bran samples (Özkaya et al., 2016). The phytic acid molecules possess a heat liable nature, which changes the permeability of the seed coat, thus reducing the phytate value (Kakati et al., 2010). Similarly, a constant decrease in the tannin content was observed on treating the germinated foxtail millet grains at increasing pressures, temperatures and times. While in case of tannin content, a minimum reduction was reported at $20{ }^{\circ} \mathrm{C}$, even on increasing pressures and soaking times at this temperature (table 2). This reduction can be attributed to the water soluble and heat liable nature of these compounds, which degrade at high temperatures and consequently leach in to the liquid medium (Kakati et al., 2010).

Therefore, on analysing the general factorial design for the process variables (pressures, soaking times and temperatures) and responses (nutritional and anti-nutritional parameters), the optimum values obtained are shown in table 3. The adjusted conditions for high pressure soaking were: $400 \mathrm{MPa}$ of pressure, $60^{\circ} \mathrm{C}$ of temperature and $60 \mathrm{~min}$ of soaking time, with a composite desirability of 0.607 for all responses. The experiments under predicted optimal conditions were repeated in triplicates to obtain mean values of all nutritional and antinutritional properties. The experimental values were found to be closer to the predicted values, thus verifying the model obtained using the general factorial design of experiment was reliable and efficient.

\section{Conclusion}

This study has shown that incorporating the processes of germination and high pressure treatment can facilitate the development nutritious products from foxtail millet. All the 
parameters of high pressure treatment, i.e. extent of pressure, temperature and soaking time, had a significant effect on the properties of germinated as well as non-germinated foxtail millet grains, but a predominant effect was that of increasing pressure and temperature. Both these processes enabled the grains to attain higher moisture content by increasing the water diffusion rates until the starch got partially gelatinized. Further, germination and high pressure processing of foxtail millet grains also resulted in significant improvements in the nutritional quality of the flour. Based on the results obtained by general factorial design, the optimum conditions for high pressure soaking were: $400 \mathrm{MPa}$ of pressure, $60{ }^{\circ} \mathrm{C}$ of temperature and $60 \mathrm{~min}$ of soaking time, with a composite desirability of 0.607 for all responses. Thus, water absorption, gelatinization and biochemical properties of foxtail millet grains can be effectively tailored using germination and a combination of high pressures and temperatures during soaking.

\section{Acknowledgement}

Nitya Sharma gratefully acknowledges the support of Commonwealth Scholarship Commission (INCN-2015-124) and Department of Food and Nutritional Sciences, University of Reading, United Kingdom. The authors have no conflict of interest.

\section{References}

Ahmed, J., Ramaswamy, H.S., Ayad, A., Alli, I., Alvarez, P., 2007. Effect of high-pressure treatment on rheological, thermal and structural changes in Basmati rice flour slurry. $\mathrm{J}$. Cereal Sci. 46, 148-156.

Ahromrit, A., Ledward, D.A., Niranjan, K., 2006. High pressure induced water uptake characteristics of Thai glutinous rice. J. Food Eng. 72, 225-233.

Ahromrit, A., Ledward, D.A., Niranjan, K., 2007. Kinetics of high pressure facilitated starch gelatinization in Thai glutinous rice. J. Food Eng. 79, 834-841.

AOAC., 1995. Official methods of analysis (15 ${ }^{\text {th }}$ ed.). Arlington, VA: AOAC International, Washington, DC. 
Bai, Q., Chai, M., Gu, Z., Cao, X., Li, Y., Liu, K., 2009. Effects of components in culture medium on glutamate decarboxylase activity and $\gamma$-aminobutyric acid accumulation in foxtail millet (Setaria italica L.) during germination. Food Chem. 116, 152-157.

Barba, F.J., Terefe, N.S., Buckow, R., Knorr, D., Orlien, V., 2015. New opportunities and perspectives of high pressure treatment to improve health and safety attributes of foods. A review. Food Res. Int. 77, 725-742.

Boluda-Aguilar, M., Taboada-Rodríguez, A., López-Gómez, A., Marín-Iniesta, F., BarbosaCánovas, G.V., 2013. Quick cooking rice by high hydrostatic pressure processing. LWT - Food Sci. Technol. 51, 196-204.

Dykes, L., Rooney, L.W., 2006. Sorghum and millet phenols and antioxidants. J. Cereal Sci. 44, 236-251.

Kakati, P., Deka, S.C., Kotoki, D., Saikia, S., 2010. Effect of traditional methods of processing on the nutrient contents and some antinutritional factors in newly developed cultivars of green gram [Vigna radiata (L.) Wilezek] and black gram [Vigna mungo (L.) Hepper] of Assam, India. Int. Food Res. J. 17, 377-384.

Karizaki, V.M., 2016. Kinetic modelling and determinations of mass transfer parameters during cooking of rice. Innov. Food Sci. Emerg. Technol. 38, 131-138.

Kashaninejad, M., Maghsoudlou, Y., Rafiee, S., Khomeiri, M., 2007. Study of hydration kinetics and density changes of rice (Tarom Mahali) during hydrothermal processing. J. Food Eng. 79, 1383-1390.

Kim, M.Y., Lee, S.H., Jang, G.Y., Li, M., Lee, Y.R., Lee, J., Jeong, H.S., 2017. Changes of phenolic-acids and vitamin $\mathrm{E}$ profiles on germinated rough rice (Oryza sativa L.) treated by high hydrostatic pressure. Food Chem. 217, 106-111.

Li, W., Bai, Y., Mousa, S.A.S., Zhang, Q., Shen, Q., 2012. Effect of high hydrostatic pressure on physicochemical and structural properties of rice starch. Food Bioprocess Technol. $5,2233-2241$.

Lii, C.Y., Lai, V.M.F., Shen, M.C., 2004. Changes in retrogradation properties of rice starches with amylose content and molecular properties. Cereal Chem. 81, 392-398.

Liu, H.S., Yu, L., Dean, K., Simon, G., Petinakis, E., Chen, L., 2009. Starch gelatinization under pressure studied by high pressure DSC. Carbohydr. Polym. 75, 395-400.

Mosavian, M.T.H., Karizaki, V.M., 2012. Determination of mass transfer parameters during deep fat frying of rice crackers. Rice Sci. 19, 64-69.

Nazni, P., Shobana, D.R., 2016. Effect of Processing on the Characteristics Changes in Barnyard and Foxtail Millet. J. Food Process. Technol. 7, 566. 
Özkaya, B., Turksoy, S., Özkaya, H., Duman, B., 2016. Dephytinization of Wheat and Rice Brans by Hydrothermal Autoclaving Process and the Evaluation of Consequences for Dietary Fiber Content, Antioxidant Activity and Phenolics. Innov. Food Sci. Emerg. Technol. 39, 209-215.

Price, M.L., Butler, L.C., 1987. Tannin and nutrition (Station Bulletin No. 272). West Lafayette, IN: Purdue University, Agriculture Experiment Station.

Qiu, S., Li, Y., Chen, H., Liu, Y., Yin, L., 2014. Effects of high-pressure homogenization on thermal and electrical properties of wheat starch. J. Food Eng. 128, 53-59.

Sharma, N., Niranjan, K., 2017. Foxtail millet: Properties, processing, health benefits, and uses. Food Rev. Int. DOI: 10.1080/87559129.2017.1290103.

Sharma, N., Goyal, S.K., Alam, T., Fatma, S., Niranjan, K., 2018. Effect of Germination on the Functional and Moisture Sorption Properties of High-Pressure-Processed Foxtail Millet Grain Flour. Food Bioprocess Technol. 11(1), 209-222.

Sharma, S., Saxena, D.C., Riar, C.S., Yildiz, F., 2015. Antioxidant activity, total phenolics, flavonoids and antinutritional characteristics of germinated foxtail millet (Setaria italica). Cogent Food Agric. 1, 1081728.

Shejawale, D.D., Hymavathi, T.V., Manorama, K., Zabeen, F., 2016. Effect of processing on nutraceutical properties of foxtail millet (Setaria italica) varieties grown in India. J. Food Measure. Charac. 10, 16-23.

Tan, F.J., Dai, W.T., Hsu, K.C., 2009. Changes in gelatinization and rheological characteristics of japonica rice starch induced by pressure/heat combinations. J. Cereal Sci. 49, 285-289.

Xia, Q., Wang, L., Xu, C., Mei, J., Li, Y., 2016. Effects of germination and high hydrostatic pressure processing on mineral elements, amino acids and antioxidants in vitro bioaccessibility, as well as starch digestibility in brown rice (Oryza sativa L.). Food Chem. 214, 533-542.

Yu, Y., Ge, L., Ramaswamy, H.S., Wang, C., Zhan, Y., Zhu, S., 2016. Effect of highpressure processing on moisture sorption properties of brown rice. Drying Technol. 34, 783-792.

Zhang, A., Liu, X., Wang, G., Wang, H., Liu, J., Zhao, W., Zhang, Y., 2015. Crude Fat Content and Fatty Acid Profile and Their Correlations in Foxtail Millet. Cereal Chem. 92, 455-459.

Zhang, L.Z., Liu, R.H., 2015. Phenolic and carotenoid profiles and antiproliferative activity of foxtail millet. Food Chem. 174, 495-501. 
Zhu, S.M., Hu, F.F., Ramaswamy, H.S., Yu, Y., Yu, L., Zhang, Q.T., 2016. Effect of High Pressure Treatment and Degree of Milling on Gelatinization and Structural Properties of Brown Rice. Food Bioprocess Technol. 9, 1844-1853.

Table 1 Effect of germination on nutritional and anti-nutritional properties of foxtail millet grains $(n=3)$.

\begin{tabular}{|c|c|c|}
\hline Properties & $\begin{array}{l}\text { Non- } \\
\text { germinated }\end{array}$ & Germinated \\
\hline Protein $(g / 100 g)$ & $10.60 \pm 0.20^{b}$ & $13.75 \pm 0.22^{\mathrm{a}}$ \\
\hline Fat $(\mathrm{g} / 100 \mathrm{~g})$ & $3.86 \pm 0.02^{\mathrm{a}}$ & $2.78 \pm 0.03^{b}$ \\
\hline Total dietary fibre $(\mathrm{g} / 100 \mathrm{~g})$ & $10.22 \pm 0.15^{\mathrm{b}}$ & $16.15 \pm 0.26^{\mathrm{a}}$ \\
\hline Total phenolic content (mg GAE/g) & $1.55 \pm 0.05^{\mathrm{b}}$ & $2.75 \pm 0.02^{\mathrm{a}}$ \\
\hline Antioxidant activity (FRAP $\left.{ }^{*}\right)(\mu \mathrm{mol} / \mathrm{g})$ & $1.79 \pm 0.02^{b}$ & $3.75 \pm 0.01^{\mathrm{a}}$ \\
\hline Phytic acid (mg/g) & $8.890 \pm 0.02^{\mathrm{a}}$ & $5.421 \pm 0.02^{b}$ \\
\hline Tannin $(\mathrm{mg} / 100 \mathrm{~g})$ & $3.040 \pm 0.03^{\mathrm{a}}$ & $1.670 \pm 0.01^{b}$ \\
\hline
\end{tabular}


Table 2 Effect on (a) protein content, (b) total phenolic content (TPC), (c) ferrous reducing antioxidant potential (FRAP), (d) phytic acid content, and (e) tannin content for germinated foxtail millet grains at different pressures, temperatures and soaking time combinations ( $\mathrm{n}=3$ ).

\begin{tabular}{|c|c|c|c|c|c|c|c|}
\hline Pressure & Time & Temperature & $\mathrm{PC}$ & TPC & FRAP & PAC & $\mathrm{TC}$ \\
\hline \multirow[t]{16}{*}{0.1} & \multirow[t]{4}{*}{30} & 20 & $13.65 \pm 0.25^{14-16}$ & $2.74 \pm 0.05^{15}$ & $3.77 \pm 0.03^{2}$ & $5.304 \pm 0.032^{25-26}$ & $1.645 \pm 0.011^{24}$ \\
\hline & & 40 & $13.55 \pm 0.30^{9-16}$ & $2.50 \pm 0.01^{14}$ & $4.30 \pm 0.04^{5-6}$ & $4.214 \pm 0.021^{16}$ & $1.587 \pm 0.020^{23-24}$ \\
\hline & & 60 & $13.70 \pm 0.22^{15-16}$ & $2.45 \pm 0.05^{13-14}$ & $4.15 \pm 0.02^{4-5}$ & $5.115 \pm 0.027^{23-25}$ & $1.533 \pm 0.017^{20-24}$ \\
\hline & & 80 & $13.71 \pm 0.20^{16}$ & $2.23 \pm 0.04^{5-13}$ & $3.94 \pm 0.03^{2-3}$ & $4.401 \pm 0.028^{17}$ & $1.564 \pm 0.015^{21-24}$ \\
\hline & \multirow[t]{4}{*}{60} & 20 & $13.60 \pm 0.21^{11-16}$ & $2.86 \pm 0.06^{15-16}$ & $3.89 \pm 0.04^{2-3}$ & $5.213 \pm 0.030^{24-26}$ & $1.638 \pm 0.022^{24}$ \\
\hline & & 40 & $13.58 \pm 0.13^{10-16}$ & $2.44 \pm 0.02^{12-14}$ & $4.38 \pm 0.05^{6-7}$ & $5.112 \pm 0.018^{23-25}$ & $1.573 \pm 0.019^{22-24}$ \\
\hline & & 60 & $13.65 \pm 0.29^{14-16}$ & $2.36 \pm 0.04^{9-14}$ & $4.36 \pm 0.02^{6-7}$ & $5.078 \pm 0.019^{23-24}$ & $1.505 \pm 0.016^{18-24}$ \\
\hline & & 80 & $13.58 \pm 0.24^{10-16}$ & $2.17 \pm 0.03^{3-11}$ & $4.02 \pm 0.06^{3-4}$ & $4.543 \pm 0.020^{17-18}$ & $1.518 \pm 0.012^{19-24}$ \\
\hline & \multirow[t]{4}{*}{90} & 20 & $13.50 \pm 0.23^{8-16}$ & $2.99 \pm 0.06^{16-18}$ & $3.92 \pm 0.02^{2-3}$ & $5.136 \pm 0.022^{23-25}$ & $1.629 \pm 0.009^{24}$ \\
\hline & & 40 & $13.60 \pm 0.24^{11-16}$ & $2.39 \pm 0.04^{10-14}$ & $4.50 \pm 0.03^{6-8}$ & $5.081 \pm 0.031^{23-24}$ & $1.560 \pm 0.008^{21-24}$ \\
\hline & & 60 & $13.71 \pm 0.24^{16}$ & $2.26 \pm 0.04^{5-14}$ & $4.39 \pm 0.03^{6-7}$ & $4.999 \pm 0.030^{22-23}$ & $1.496 \pm 0.020^{18-24}$ \\
\hline & & 80 & $13.63 \pm 0.30^{13-16}$ & $2.13 \pm 0.05^{3-10}$ & $3.59 \pm 0.04^{1}$ & $4.641 \pm 0.017^{18-19}$ & $1.475 \pm 0.021^{17-24}$ \\
\hline & \multirow[t]{4}{*}{120} & 20 & $13.54 \pm 0.28^{9-16}$ & $3.04 \pm 0.04^{16-18}$ & $3.97 \pm 0.05^{3-4}$ & $5.130 \pm 0.020^{23-25}$ & $1.625 \pm 0.019^{24}$ \\
\hline & & 40 & $13.70 \pm 0.25^{15-16}$ & $2.31 \pm 0.04^{7-14}$ & $4.69 \pm 0.06^{8-10}$ & $4.952 \pm 0.022^{21-23}$ & $1.537 \pm 0.023^{20-24}$ \\
\hline & & 60 & $13.70 \pm 0.28^{15-16}$ & $2.25 \pm 0.05^{5-14}$ & $4.50 \pm 0.03^{6-8}$ & $4.885 \pm 0.014^{20-22}$ & $1.472 \pm 0.015^{17-24}$ \\
\hline & & 80 & $13.65 \pm 0.32^{14-16}$ & $2.12 \pm 0.06^{3-9}$ & $4.32 \pm 0.05^{5-6}$ & $4.736 \pm 0.015^{18-20}$ & $1.449 \pm 0.010^{17-24}$ \\
\hline \multirow[t]{15}{*}{200} & \multirow[t]{4}{*}{30} & 20 & $13.55 \pm 0.20^{9-16}$ & $2.88 \pm 0.05^{15-16}$ & $4.53 \pm 0.03^{7-8}$ & $5.328 \pm 0.033^{26}$ & $1.628 \pm 0.01^{24}$ \\
\hline & & 40 & $13.70 \pm 0.28^{15-16}$ & $2.26 \pm 0.04^{5-14}$ & $4.96 \pm 0.03^{11-12}$ & $3.678 \pm 0.031^{15}$ & $1.559 \pm 0.022^{21-24}$ \\
\hline & & 60 & $13.21 \pm 0.17^{1-5}$ & $2.13 \pm 0.03^{3-10}$ & $4.74 \pm 0.03^{9-10}$ & $3.335 \pm 0.027^{13-14}$ & $1.440 \pm 0.020^{16-24}$ \\
\hline & & 80 & $13.62 \pm 0.22^{12-16}$ & $2.00 \pm 0.02^{1-5}$ & $4.61 \pm 0.02^{8-9}$ & $3.064 \pm 0.028^{11-12}$ & $1.390 \pm 0.021^{15-23}$ \\
\hline & \multirow[t]{4}{*}{60} & 20 & $13.38 \pm 0.23^{4-11}$ & $2.92 \pm 0.04^{15-17}$ & $4.81 \pm 0.02^{10-11}$ & $5.400 \pm 0.021^{26}$ & $1.573 \pm 0.017^{22-24}$ \\
\hline & & 40 & $13.40 \pm 0.27^{4-12}$ & $2.26 \pm 0.01^{5-14}$ & $5.31 \pm 0.02^{14-15}$ & $3.216 \pm 0.030^{12-13}$ & $1.491 \pm 0.016^{18-24}$ \\
\hline & & 60 & $13.22 \pm 0.25^{1-6}$ & $2.07 \pm 0.03^{1-8}$ & $5.09 \pm 0.06^{12-13}$ & $3.167 \pm 0.024^{11-13}$ & $1.370 \pm 0.010^{14-23}$ \\
\hline & & 80 & $13.43 \pm 0.18^{5-14}$ & $2.04 \pm 0.05^{1-6}$ & $4.87 \pm 0.05^{10-11}$ & $2.996 \pm 0.023^{11}$ & $1.317 \pm 0.011^{14-20}$ \\
\hline & \multirow[t]{4}{*}{90} & 20 & $13.42 \pm 0.30^{5-13}$ & $3.04 \pm 0.04^{16-18}$ & $4.97 \pm 0.02^{11-12}$ & $5.240 \pm 0.017^{24-26}$ & $1.550 \pm 0.020^{21-24}$ \\
\hline & & 40 & $13.35 \pm 0.27^{3-9}$ & $2.14 \pm 0.01^{3-10}$ & $5.49 \pm 0.03^{15-17}$ & $3.441 \pm 0.012^{14}$ & $1.462 \pm 0.018^{17-24}$ \\
\hline & & 60 & $13.21 \pm 0.26^{1-5}$ & $2.04 \pm 0.03^{1-6}$ & $5.32 \pm 0.03^{14-15}$ & $2.981 \pm 0.032^{11}$ & $1.347 \pm 0.017^{14-22}$ \\
\hline & & 80 & $13.31 \pm 0.31^{2-8}$ & $1.85 \pm 0.04^{1-2}$ & $5.19 \pm 0.02^{13-14}$ & $2.575 \pm 0.019^{10}$ & $1.259 \pm 0.022^{12-17}$ \\
\hline & \multirow[t]{3}{*}{120} & 20 & $13.40 \pm 0.20^{4-12}$ & $3.09 \pm 0.02^{16-18}$ & $5.33 \pm 0.02^{14-15}$ & $5.114 \pm 0.023^{23-25}$ & $1.492 \pm 0.015^{18-24}$ \\
\hline & & 40 & $13.42 \pm 0.38^{5-13}$ & $2.13 \pm 0.01^{3-10}$ & $5.77 \pm 0.02^{18-20}$ & $3.043 \pm 0.031^{11-12}$ & $1.436 \pm 0.013^{16-24}$ \\
\hline & & 60 & $13.30 \pm 0.15^{2-8}$ & $1.93 \pm 0.03^{1-4}$ & $5.63 \pm 0.03^{17-18}$ & $2.525 \pm 0.015^{10}$ & $1.290 \pm 0.010^{13-18}$ \\
\hline
\end{tabular}




\begin{tabular}{|c|c|c|c|c|c|c|c|}
\hline & & 80 & $13.22 \pm 0.20^{1-6}$ & $1.84 \pm 0.03^{1}$ & $5.42 \pm 0.03^{15-16}$ & $2.328 \pm 0.025^{9}$ & $1.191 \pm 0.018^{12-15}$ \\
\hline \multirow[t]{16}{*}{400} & 30 & 20 & $13.63 \pm 0.18^{13-16}$ & $2.92 \pm 0.04^{15-17}$ & $5.31 \pm 0.03^{14-15}$ & $4.809 \pm 0.020^{19-21}$ & $1.625 \pm 0.010^{24}$ \\
\hline & & 40 & $13.42 \pm 0.23^{5-13}$ & $2.43 \pm 0.04^{11-14}$ & $5.89 \pm 0.04^{20-21}$ & $2.127 \pm 0.030^{8}$ & $1.294 \pm 0.01^{13-18}$ \\
\hline & & 60 & $13.35 \pm 0.25^{3-9}$ & $2.32 \pm 0.03^{8-14}$ & $5.69 \pm 0.03^{18-19}$ & $2.034 \pm 0.025^{5-8}$ & $1.071 \pm 0.017^{9-12}$ \\
\hline & & 80 & $13.25 \pm 0.20^{1-7}$ & $2.32 \pm 0.04^{8-14}$ & $5.59 \pm 0.03^{16-18}$ & $1.877 \pm 0.018^{2-6}$ & $0.980 \pm 0.009^{8-11}$ \\
\hline & 60 & 20 & $13.48 \pm 0.19^{8-15}$ & $3.11 \pm 0.01^{16-18}$ & $5.64 \pm 0.03^{17-18}$ & $4.795 \pm 0.023^{19-21}$ & $1.550 \pm 0.010^{21-24}$ \\
\hline & & 40 & $13.36 \pm 0.29^{3-10}$ & $2.39 \pm 0.02^{10-14}$ & $6.10 \pm 0.03^{22-23}$ & $1.991 \pm 0.029^{4-8}$ & $1.225 \pm 0.008^{12-16}$ \\
\hline & & 60 & $13.18 \pm 0.15^{1-4}$ & $2.27 \pm 0.02^{6-14}$ & $5.97 \pm 0.02^{21-22}$ & $1.904 \pm 0.018^{2-7}$ & $0.982 \pm 0.009^{8-11}$ \\
\hline & & 80 & $13.33 \pm 0.20^{2-9}$ & $2.21 \pm 0.05^{5-13}$ & $5.84 \pm 0.02^{19-21}$ & $1.827 \pm 0.015^{1-4}$ & $0.891 \pm 0.012^{6-10}$ \\
\hline & 90 & 20 & $13.50 \pm 0.25^{8-16}$ & $3.15 \pm 0.03^{17-18}$ & $5.85 \pm 0.04^{19-21}$ & $4.722 \pm 0.013^{18-20}$ & $1.531 \pm 0.015^{20-24}$ \\
\hline & & 40 & $13.34 \pm 0.28^{3-9}$ & $2.26 \pm 0.02^{5-14}$ & $6.39 \pm 0.05^{24-25}$ & $1.965 \pm 0.011^{3-8}$ & $1.161 \pm 0.011^{11-14}$ \\
\hline & & 60 & $13.21 \pm 0.11^{1-5}$ & $2.18 \pm 0.03^{3-12}$ & $6.33 \pm 0.03^{24-25}$ & $1.826 \pm 0.021^{1-4}$ & $0.949 \pm 0.012^{7-10}$ \\
\hline & & 80 & $13.05 \pm 0.13^{1}$ & $2.15 \pm 0.03^{3-10}$ & $6.03 \pm 0.02^{21-22}$ & $1.765 \pm 0.030^{1-3}$ & $0.835 \pm 0.006^{5-8}$ \\
\hline & 120 & 20 & $13.45 \pm 0.21^{7-14}$ & $3.18 \pm 0.04^{18}$ & $6.03 \pm 0.03^{21-22}$ & $4.657 \pm 0.025^{18-19}$ & $1.485 \pm 0.009^{18-24}$ \\
\hline & & 40 & $13.37 \pm 0.27^{3-10}$ & $2.21 \pm 0.03^{5-13}$ & $6.68 \pm 0.02^{27-28}$ & $1.846 \pm 0.027^{2-6}$ & $1.095 \pm 0.010^{10-13}$ \\
\hline & & 60 & $13.15 \pm 0.10^{1-3}$ & $2.13 \pm 0.04^{3-10}$ & $6.49 \pm 0.03^{25-26}$ & $1.739 \pm 0.025^{1-2}$ & $0.875 \pm 0.007^{5-9}$ \\
\hline & & 80 & $13.05 \pm 0.12^{1}$ & $1.86 \pm 0.02^{1-2}$ & $6.27 \pm 0.02^{23-24}$ & $1.644 \pm 0.030^{1}$ & $0.722 \pm 0.008^{3-6}$ \\
\hline \multirow[t]{16}{*}{600} & 30 & 20 & $13.65 \pm 0.23^{14-16}$ & $3.03 \pm 0.03^{16-18}$ & $6.44 \pm 0.02^{24-25}$ & $4.871 \pm 0.01^{20-22}$ & $1.635 \pm 0.012^{24}$ \\
\hline & & 40 & $13.44 \pm 0.30^{6-14}$ & $2.43 \pm 0.02^{11-14}$ & $7.08 \pm 0.03^{30}$ & $2.100 \pm 0.018^{7-8}$ & $1.095 \pm 0.014^{10-13}$ \\
\hline & & 60 & $13.25 \pm 0.18^{1-7}$ & $2.23 \pm 0.01^{5-13}$ & $6.85 \pm 0.03^{28-29}$ & $2.021 \pm 0.022^{4-8}$ & $0.761 \pm 0.009^{4-7}$ \\
\hline & & 80 & $13.22 \pm 0.20^{1-6}$ & $2.28 \pm 0.01^{6-14}$ & $6.64 \pm 0.04^{26-27}$ & $1.977 \pm 0.023^{4-8}$ & $0.615 \pm 0.007^{1-4}$ \\
\hline & 60 & 20 & $13.63 \pm 0.33^{13-16}$ & $3.07 \pm 0.03^{16-18}$ & $6.69 \pm 0.04^{27-28}$ & $4.730 \pm 0.030^{18-20}$ & $1.535 \pm 0.010^{20-24}$ \\
\hline & & 40 & $13.33 \pm 0.21^{2-9}$ & $2.34 \pm 0.04^{9-14}$ & $7.34 \pm 0.04^{31-32}$ & $2.041 \pm 0.029^{6-8}$ & $0.874 \pm 0.011^{5-9}$ \\
\hline & & 60 & $13.18 \pm 0.15^{1-4}$ & $2.15 \pm 0.04^{3-10}$ & $7.12 \pm 0.02^{30}$ & $1.979 \pm 0.013^{4-8}$ & $0.670 \pm 0.006^{2-5}$ \\
\hline & & 80 & $13.25 \pm 0.24^{1-7}$ & $2.19 \pm 0.05^{4-13}$ & $6.89 \pm 0.03^{29}$ & $1.994 \pm 0.011^{4-8}$ & $0.557 \pm 0.009^{1-4}$ \\
\hline & 90 & 20 & $13.48 \pm 0.20^{8-15}$ & $3.20 \pm 0.05^{18}$ & $7.08 \pm 0.03^{30}$ & $4.746 \pm 0.030^{19-20}$ & $1.417 \pm 0.012^{16-24}$ \\
\hline & & 40 & $13.28 \pm 0.16^{2-8}$ & $2.22 \pm 0.06^{5-13}$ & $7.56 \pm 0.04^{33-34}$ & $1.971 \pm 0.014^{4-8}$ & $0.755 \pm 0.009^{4-7}$ \\
\hline & & 60 & $13.33 \pm 0.12^{2-9}$ & $2.05 \pm 0.06^{1-7}$ & $7.44 \pm 0.04^{32-33}$ & $1.940 \pm 0.019^{2-8}$ & $0.575 \pm 0.007^{1-4}$ \\
\hline & & 80 & $13.18 \pm 0.10^{1-4}$ & $2.10 \pm 0.04^{2-9}$ & $7.25 \pm 0.03^{30-31}$ & $1.837 \pm 0.020^{1-6}$ & $0.467 \pm 0.008^{1-2}$ \\
\hline & 120 & 20 & $13.63 \pm 0.31^{13-16}$ & $3.21 \pm 0.06^{18}$ & $7.20 \pm 0.02^{30-31}$ & $4.654 \pm 0.032^{18-19}$ & $1.335 \pm 0.010^{14-21}$ \\
\hline & & 40 & $13.21 \pm 0.20^{1-5}$ & $2.18 \pm 0.03^{3-12}$ & $7.85 \pm 0.04^{35}$ & $1.874 \pm 0.019^{2-6}$ & $0.611 \pm 0.007^{1-4}$ \\
\hline & & 60 & $13.25 \pm 0.15^{1-7}$ & $2.02 \pm 0.04^{1-6}$ & $7.69 \pm 0.03^{34-35}$ & $1.834 \pm 0.024^{1-5}$ & $0.522 \pm 0.005^{1-3}$ \\
\hline & & 80 & $13.11 \pm 0.18^{1-2}$ & $1.92 \pm 0.02^{1-3}$ & $7.53 \pm 0.02^{33-34}$ & $1.859 \pm 0.027^{2-6}$ & $0.425 \pm 0.006^{1}$ \\
\hline
\end{tabular}


1 Table 3 Experimental and model predicted values of nutritional and anti-nutritional properties at adjusted conditions of high pressure soaking $\left(400 \mathrm{MPa}, 60{ }^{\circ} \mathrm{C}\right.$ and 60 mins) as evaluated using General factorial design model $(n=3)$.

\begin{tabular}{|c|c|c|c|}
\hline Properties & $\begin{array}{c}\text { Experimental } \\
\text { value }\end{array}$ & $\begin{array}{c}\text { Predicted } \\
\text { value }\end{array}$ & $\begin{array}{c}\text { Individual } \\
\text { desirability }\left(d_{i}\right)\end{array}$ \\
\hline Protein $(g / 100 g)$ & $13.50 \pm 0.18^{\mathrm{a}}$ & $13.44 \pm 0.22^{\mathrm{a}}$ & 0.591 \\
\hline TPC (mg GAE/g) & $2.98 \pm 0.08^{\mathrm{a}}$ & $2.93 \pm 0.11^{\mathrm{a}}$ & 0.820 \\
\hline $\operatorname{FRAP}^{*}(\mu \mathrm{mol} / \mathrm{g})$ & $7.02 \pm 0.10^{\mathrm{a}}$ & $7.08 \pm 0.09^{\mathrm{a}}$ & 0.428 \\
\hline Phytic acid (mg/g) & $2.100 \pm 0.090^{\mathrm{a}}$ & $2.099 \pm 0.089^{\mathrm{a}}$ & 0.879 \\
\hline Tannin (mg/100g) & $1.088 \pm 0.101^{\mathrm{a}}$ & $1.095 \pm 0.091^{\mathrm{a}}$ & 0.450 \\
\hline
\end{tabular}

6

7

8

9 
a) Interaction Plot for Water Uptake for Germinated grains (\%) Date Means

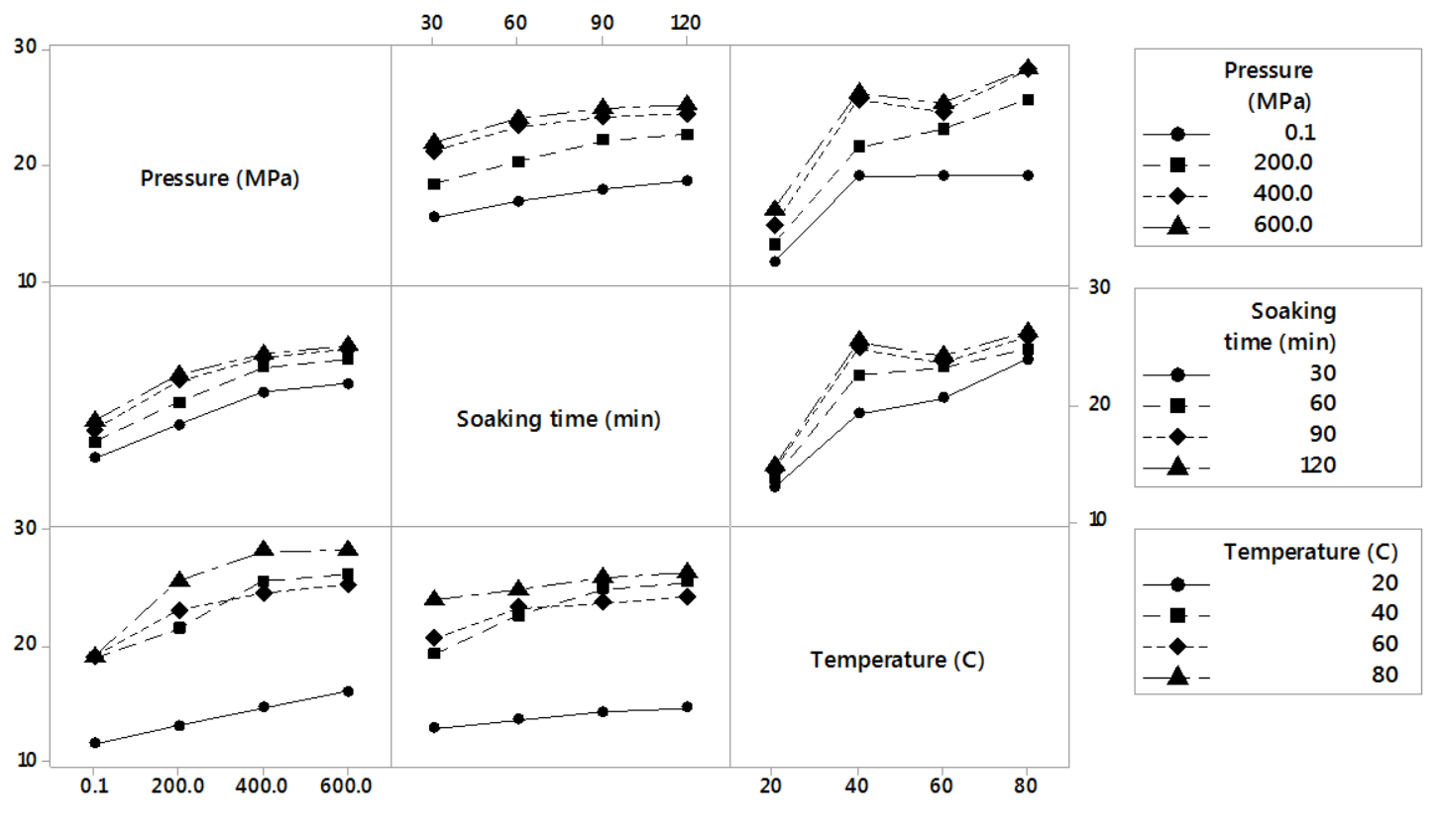

b) Interaction Plot for Water Uptake for Non-Germinated grains (\%) Date Means

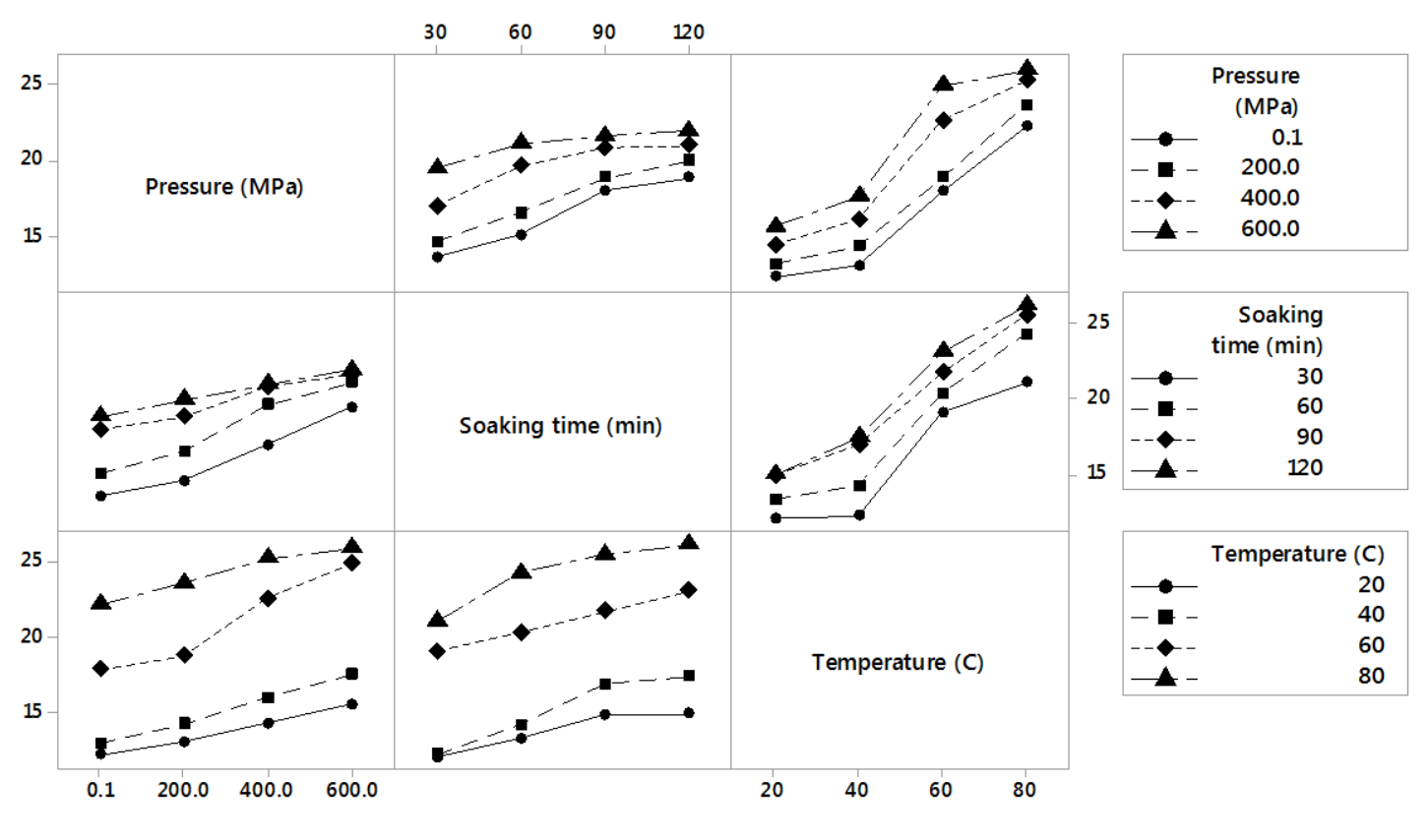

Fig. 1. Interaction plot for water uptake by (a) germinated and (b) non-germinated foxtail millet grains, as a function of soaking time at different pressures and temperatures $(n=3)$. 
(a) Germinated grains

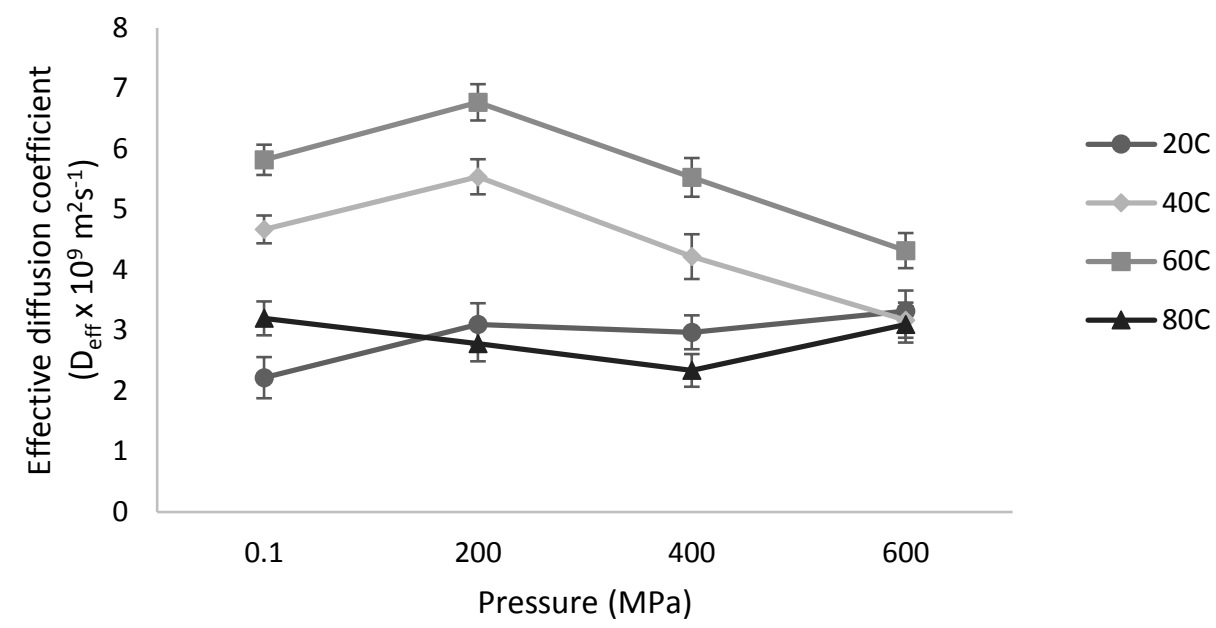

15

(b) Non-germinated grains

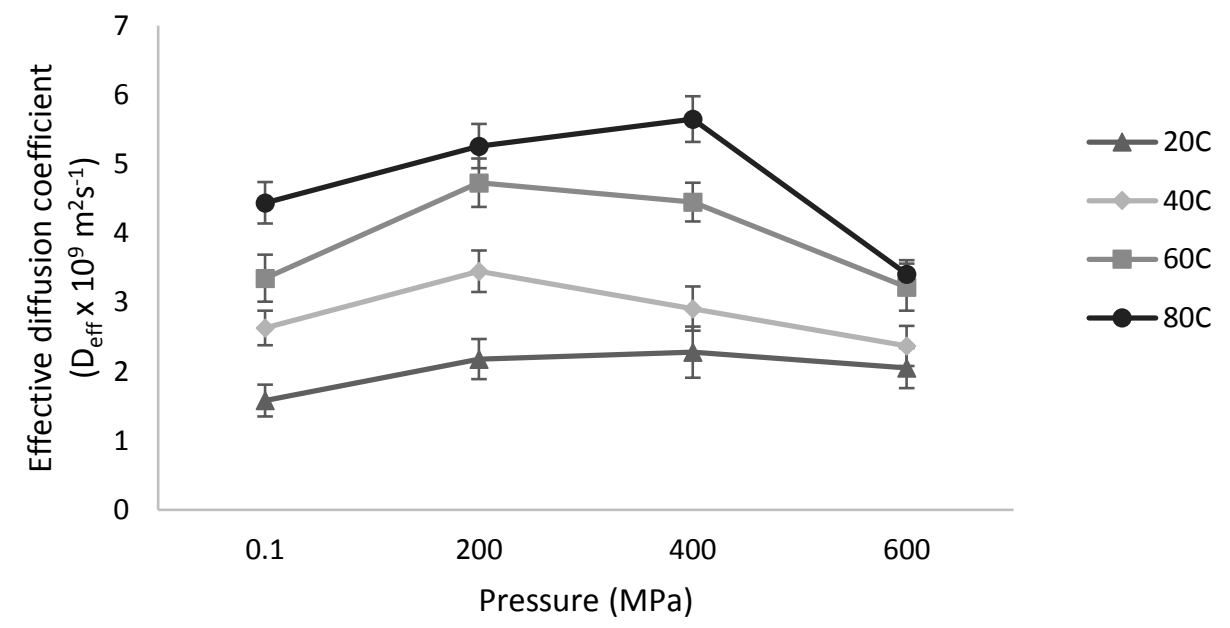

17

18 Fig. 2. Variation of effective diffusion coefficient $\left(D_{\text {eff }}\right)$ with soaking pressures and 19 temperatures for (a) germinated and (b) non-germinated foxtail millet grains $(n=3)$. Error bars denote the standard deviation. 
a) Interaction Plot for Starch Gelatinization for Germinated grains (\%) Date Means

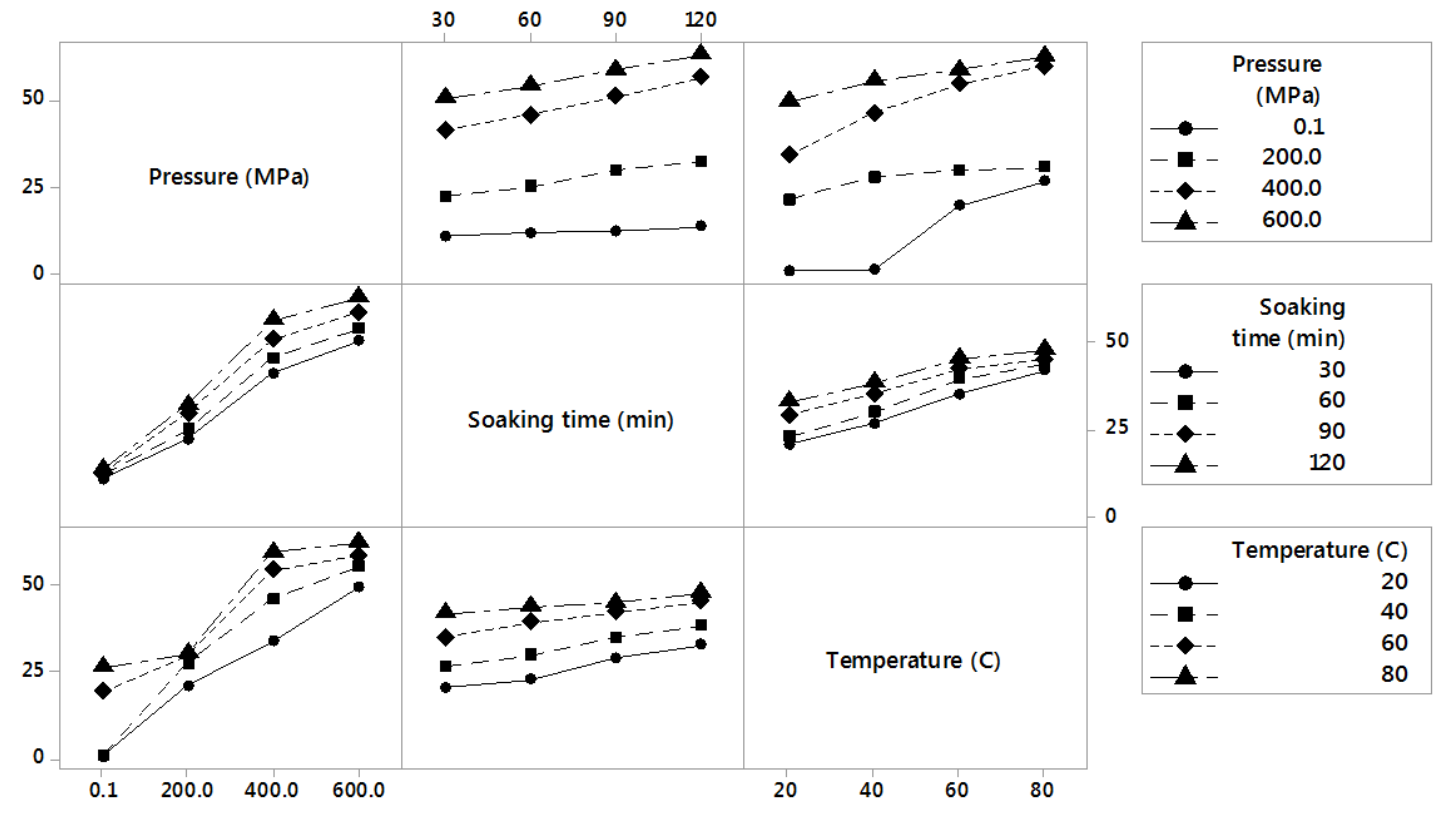

b) Interaction Plot for Starch Gelatinization for Non-Germinated grains (\%) Date Means

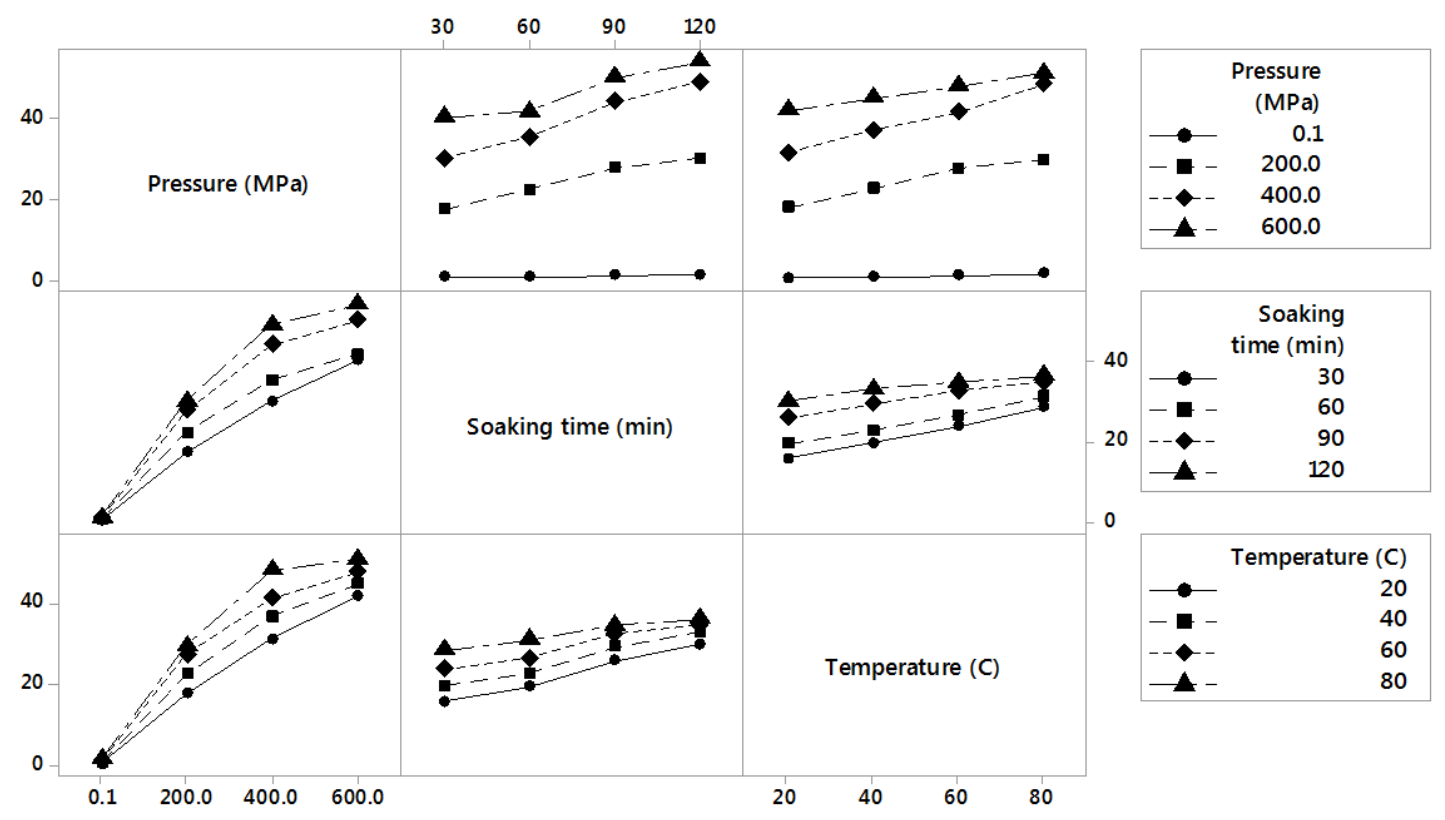

Fig. 3. Interaction plots for degree of starch gelatinization for (a) germinated and (b) nongerminated foxtail millet grains as a function of soaking time at different pressures and temperatures $(n=3)$. 
